\title{
First report of Basidiolum fimbriatum since 1861, with comments on its development, occurrence, distribution and relationship with other fungi
}

\author{
Merlin M. WHITE \\ Department of Ecology and Evolutionary Biology, University of Kansas, Lawrence, Kansas, 66045-2106, USA. \\ E-mail:trichos@ku.edu
}

Received 1 October 2002; accepted 19 December 2002.

\begin{abstract}
An obscure parasitic fungus, Basidiolum fimbriatum, was found on Amoebidium parasiticum (Amoebidiales) associated with Caenis sp. (mayfly) nymphs, during a survey of gut fungi (Trichomycetes) from a small stream in northeastern Kansas, USA. The hindguts of the nymphs harboured a species of Legeriomycetaceae and Paramoebidium sp. This is the first report of the ectocommensal protozoan, A. parasiticum, associated with the gills of Caenidae (Ephemeroptera), and of B. fimbriatum in the 142 years since its original documentation from Wiesbaden, Germany. B. fimbriatum is recorded from two midwestern USA states (Kansas and Iowa) and the morphological and developmental features of the parasite on its host are compared with Cienkowski's original observations and interpretation. B. fimbriatum is characterized as a parasitic fungus possessing merosporangia that form on a simple pyriform thallus that penetrates and consumes its host via a haustorial network. The hypothesis that B. fimbriatum is most closely related to members of the order Zoopagales sensu Benjamin (1979) is proposed. The importance of future collections and molecular-based phylogenetic approaches to place this parasitic fungus within a current system of classification are highlighted.
\end{abstract}

\section{INTRODUCTION}

Basidiolum fimbriatum Cienkowski (1861) is one of the more obscure microscopic fungi. Hawksworth et al. (1995) included only the original citation for B. fimbriatum (Cienkowski 1861) and I believe that this is the first report of the fungus since that publication. At the time, Cienkowski (1861) was expanding on earlier reports by Lieberkühn (1856) and Schenk (1858) to detail further observations on the ontogeny of an enigmatic ectocommensal, associated with caddisfly (Trichoptera) and mosquito larvae as well as freshwater amphipods. He proposed the name Amoebidium parasiticum for the ectocommensal and illustrated it with a plate including 39 figures. However, 10 of the 39 figures also depicted a parasite on $A$. parasiticum which he named B. fimbriatum (Figs 14-20).

Amoebidium parasiticum has a known worldwide distribution associated with various aquatic Crustacea and Insecta (Lichtwardt 1986; http://ron.nhm.ukans. edu/ fungi). Attached with a secreted holdfast (Whisler \& Fuller 1968), it forms an unbranched thallus and can produce sporangiospores or amoeboid cells from the entire protoplast that in turn may encyst and form cystospores. Two genera, Amoebidium and Paramoebidium (whose species are all endobionts in the guts of larval aquatic insects) comprise the Amoebidiales, one of four orders originally classified as Trichomycetes
(Zygomycota), more commonly known as gut fungi (Lichtwardt 1986). The inclusion of Amoebidiales within the Trichomycetes has been more a matter of convenience rather than an indication of any natural affinity. It is not uncommon for those studying gut fungi to encounter species of Amoebidiales, also associated with various arthropod hosts. Lichtwardt (1986) suggested that the Amoebidiales were not closely related to the other three orders of Trichomycetes, a notion which has been confirmed using sequence data to establish A. parasiticum as a protozoan (Benny \& O'Donnell 2000, Ustinova, Krienitz \& Huss 2000). Recent molecular based phylogenies place this species near the animalfungal divergence (Mendoza, Taylor \& Ajello 2002).

The taxonomic placement of the ectoparasite of A. parasiticum, B. fimbriatum, is enigmatic and remains an open question. Cienkowski (1861) called the ectoparasite Basidiolum, owing to the resemblance of the thallus to the basidium of higher fungi and used the epithet fimbriatum, because of its spore formation and appearance at maturity (bearing resemblance to tassels). Despite the relatively frequent observation of A. parasiticum, one of four species of the genus (Misra \& Lichtwardt 2000), there have been no reports of B. fimbriatum since its original documentation from Wiesbaden, Germany. The intent of this report is to review and augment Cienkowski's observations of this ectoparasite, to record the known occurrences of 
B. fimbriatum, and to comment on its possible taxonomic affinity with other fungi.

\section{MATERIALS AND METHODS}

Caenidae (Ephemeroptera) were included among an assortment of aquatic insect larvae collected by each of three undergraduate classes from Buck Creek, a small lotic system in Jefferson County, just north of Lawrence, Kansas $\left(39^{\circ} 06^{\prime} \mathrm{N}, 95^{\circ} 17.2^{\prime} \mathrm{W}\right), 20-23$ April 1998. Using a kick sampling technique, mayfly nymphs were dislodged from the stream bottom and collected with an aquatic sampling net. Caenis sp. nymphs, commonly found in slowly flowing, silted parts of the stream, were maintained in plastic collecting jars with minimal stream water at $4-10{ }^{\circ} \mathrm{C}$ for a few to several days after collection. Hindguts of the nymphs were removed with fine forceps and manipulated with dissecting pins before wet mounting to identify Trichomycetes. Gills were removed and mounted separately in water. Infested gills were examined at higher magnification (using phase and Nomarski interference contrast optics) and photographed (Kodak Ektachrome 320T film) before infiltrating the specimens with lactophenol cotton blue and sealing cover glasses with fingernail polish. An attempt was made to culture Amoebidium and its fungal parasite by placing infested gills on plates of dilute brain-heart infusion agar and tryptone-glucosesalts agar medium, each with a distilled water overlayer and antibiotic solution (Lichtwardt 1986). Subsequently, images of fixed material on semi-permanent slides were obtained using a Nikon Coolpix 950 digital camera. Preserved slides of specimens have been deposited at FH. The following is a list of slides (KS-) or Ektachromes (KU-) deposited with corresponding figure numbers: Figs 1-2 \& 9, Slide KS-58-W4, Ektachromes KU-31926, KU-319-27, KU-319-30; Figs 3, 8 \& 11, KS-58-W6, KU-319-33, KU-319-34; KU-319-36; Fig. 4, KS-58W10b), KU-320-3; Figs 5-6, KS-58-W6b), KU-320-7, KU-320-8; Fig. 7, KS-58-W6a), KU-320-4; Figs 10 \& 12, KS-58-W10, KU-320-2, KU-320-1; Fig. 13, KS58-W11b).

\section{RESULTS}

Caenid nymphs were selected for dissection to identify Trichomycetes from their hindguts because in several previous surveys, at this site, they had been shown repeatedly to harbour a species of Legeriomycetaceae (Harpellales). Eight of eleven nymphs dissected harboured non-sexual stages of a branched gut fungus and four of eleven also included Paramoebidium sp. The gut fungus will not be identified at this time because sexual stages necessary for proper identification have not been observed.

The operculate gills of these immature mayflies, appearing as two dorsal flaps on the abdomens of the nymphs, provide protection and permit water movement across the lamellate gills below. While the nymphs tended to be covered with silt, the gills were

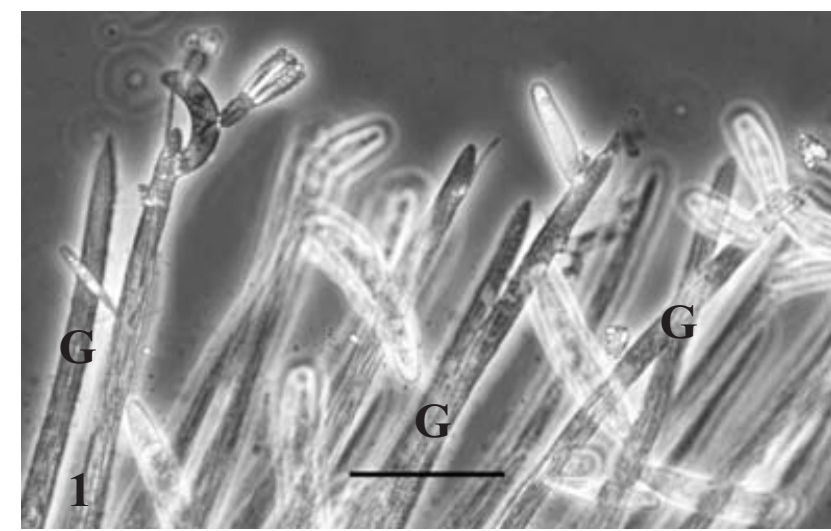

Fig. 1. Gill lamellae (G) of Caenis sp. with various developmental stages of Amoebidium parasiticum (refractive), one of which (upper left) is parasitized by a mature Basidiolum fimbriatum. Bar $=50 \mu \mathrm{m}$.

comparatively free of debris except that all eight of those examined externally were lightly to heavily infested with $A$. parasiticum. Five of the eight infested nymphs included $B$. fimbriatum parasitizing the ectocommensals (Fig. 1) and all developmental stages of the parasite were observed.

Cienkowski's (1861) original description is detailed and sufficient for species identification but is more concisely stated below, with terminology that reflects a contemporary understanding and interpretation of the morphology and ontogeny of the parasite.

Basidiolum fimbriatum Cienkowski, Bot. Zeit. 19: 169 (1861).

Thallus pyriform to ovoid, to $10 \times 20 \mu \mathrm{m}$, attached at narrowed base. Thallus sometimes thickened at base and refractive. Spores cuboidal to spherical, 3-4 $\mu \mathrm{m}$ diam, non-motile, released upon the deliquescence of the merosporangium. Merosporangia form on broad distal surface of the thallus, initially as 'knob-like' projections. Spores adhere to surface of host and enlarge to become a spore-producing thallus. Haustorial penetration of host initiated upon spore attachment, apparent with distortion of outer wall of host or slight swelling just beneath the penetrated thallus wall. Upon penetration and ramification, haustoria unevenly thickened, eventually consuming the contents of the host. Sexual reproduction unknown.

Known only as a parasite on Amoebidium.

Initially $B$. fimbriatum thalli were noted as projections on the surface of Amoebidium, often accompanied by a transparency of the parasitized specimens (using phase contrast optics with fresh material) (Figs 1-2). In mature stages of parasitism, spores were observed as chains on the distal surface of the thallus body (Figs 2-3). Sporangia developed from outgrowths (Figs 4, $7,9-10)$ of the thallus proper or sporophore (i.e. the merosporangial type of development). Sporophores were occasionally curved at the base (Fig. 4). Nonmotile spores were observed disarticulating from mature merosporangia (Figs 2-3) upon deliquescence of the 

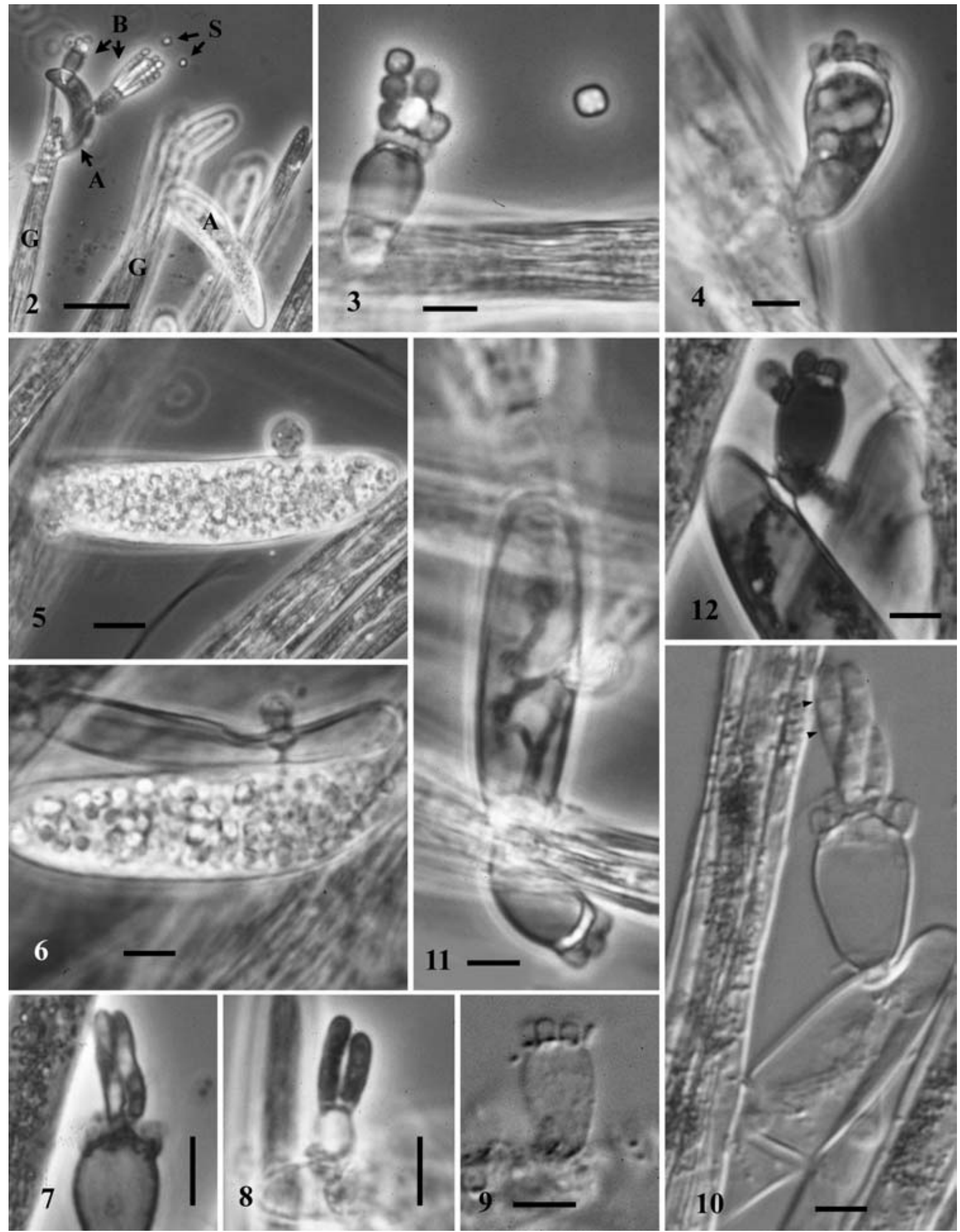

Figs 2-12. Phase contrast $(2-8,11,12)$ and Nomarski $(9,10)$ microscopy of Basidiolum fimbriatum (B) parasitizing Amoebidium parasiticum (A) attached to the lamellae $(\mathrm{G})$ of Caenis sp. nymphs. Fig. 2. Overview of infested gill with two thalli of B. fimbriatum parasitizing an Amoebidium thallus. Two spores (in focus) are drifting away from deliquescent merosporangia. Fig. 3. Mature merosporangia with disseminating spore possessing four refractive bodies. Fig. 4. Slightly bent thallus of B. fimbriatum attached to A. parasiticum. Fig. 5. Enlarged spore of B. fimbriatum attached to A. parasiticum. Fig. 6. Sporangiospore of $A$. parasiticum, showing haustorial penetration through detached sporangial wall of host. Figs 7-8. Immature B. fimbriatum merosporangia of similar size, borne on sporophores of different size. Fig. 9. Thallus showing outgrowths where merosporangia are formed. Fig. 10. Thallus with three, twisted merosporangia, undergoing spore division internally (arrowheads). Host wall penetration, indicated by wall distortion and basal swelling, with haustorial growth evident. Fig. 11. Three attached parasites (two in focus) and extensive haustorial ramification with swollen junctures giving knotted appearance. Fig. 12. Thickened refractive base of thallus with haustoria evident, extending from point of penetration of host. Bars: Fig. $2=25 \mu \mathrm{m}$, Figs $3-12=5 \mu \mathrm{m}$. 


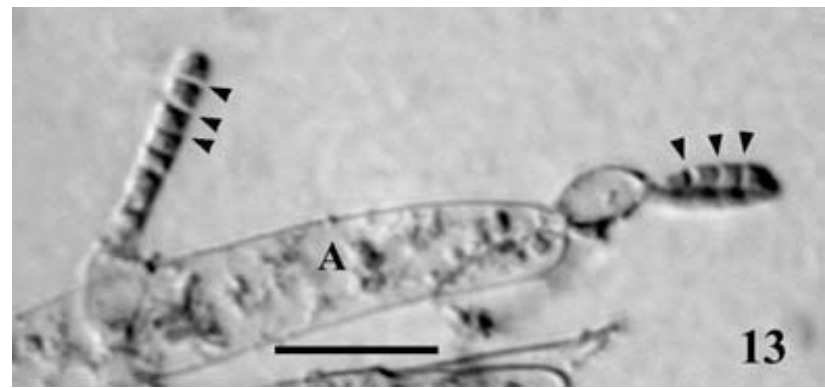

Fig. 13. Stained specimen, clearly indicating spore delimitation (arrowheads) of immature merosporangia in two thalli of Basidiolum fimbriatum attached to thallus of Amoebidium parasiticum (A). Bar $=25 \mu \mathrm{m}$.

sporangial wall, with as many as four distinct refractive inclusions (Fig. 3). Some spores were attached to otherwise apparently healthy thalli of $A$. parasiticum (Fig. 5). In some cases, penetration of the host wall occurred soon after spore attachment and prior to maturation of the parasitic thalli (Fig. 6). Intermediate stages exhibited sporangia with a distinct wall, typical of merosporangial development (Figs 7-8, 10). The sporophore of some specimens had merosporangia developing from outgrowths of the distal surface (Figs 7-8) with evidence of spore delimitation in some instances (Fig. 10, arrowheads). Advanced stages of development were observed with haustoria inside the evacuated thalli of the $A$. parasiticum (Figs 1-2, 10-12). With further development, haustoria were thickened, sometimes appearing unevenly swollen with ramification throughout the host (Figs 2, 10-12). Several specimens indicated an apparent adhesion to the host thallus (Figs 5, 12), host wall distortion (Figs 6,10) and various stages of host penetration (Figs 2, 6, 10-12). After lactophenol cotton blue infiltration of immature merosporangia, lines of spore delimitation were clearly revealed (Fig. 13, arrowheads).

Culture attempts were unsuccessful. After several weeks on plates, microscopic examination of gills revealed spherical encysted amoebae of $A$. parasiticum with no indication of $B$. fimbriatum present.

\section{DISCUSSION}

Caenidae have been reported once as hosts of gut fungi. Allantomyces caenidarum M. C. Williams \& Lichtw. 1993 and Legeriomyces rarus Lichtw. \& M. C. Williams 1993 were reported in the hindguts of Tasmanocoenis sp. nymphs from Western Australia (Williams \& Lichtwardt 1993). The branched species of Harpellales in Caenidae from the midwestern USA is Legeriomyceslike but I decline to name it because species identification would be premature without studying the sexual stages (White 1999). The Legeriomyces-like gut fungus occasionally attaches to Paramoebidium sp. thalli rather than to the gut lining, a feature that has not been noted with species of Legeriomyces previously, but is typical of Simuliomyces microsporus Lichtw. 1972 (Lichtwardt 1986). Paramoebidium, the other genus of Amoebidiales, differs from Amoebidium in that species are restricted to the guts of various larval aquatic insects and lack the sporangiospore stage of Amoebidium (Lichtwardt 1986). Paramoebidium species are common inhabitants of mayfly nymph guts but the species diversity of both genera of Amoebidiales may be vastly underestimated because of limited morphological features available to differentiate them and the range of variation that is possible within any species or collection.

This is the first report of $A$. parasiticum on Caenid gills, yet another host among the many that have been reported (Lichtwardt 1986). The specimens discovered in northeastern Kansas have provided the first report of B. fimbriatum since Cienkowski's observations of it 142 years ago. However, I am aware of one other known occurrence of $B$. fimbriatum. The parasite was identified on $A$. parasiticum from a collection of daphnids and mosquito larvae collected on 26 July 1984, from a mud hole on a rutted road at the entrance to Milford Woods, on the southwest shore of Okoboji Lake, Dickinson County, northwest Iowa $\left(43^{\circ} 19.6^{\prime} \mathrm{N}, 95^{\circ} 11.8^{\prime} \mathrm{W}\right)$ (Lichtwardt, unpubl.). It is reasonable to assume that such a disparate distribution and infrequent occurrence is a reflection of the very small size of the parasite and the few researchers who may have had the opportunity to encounter and recognize it. It is quite possible that the parasite occurs more commonly and is more widely dispersed than is currently known. Presumably, Basidiolum fimbriatum may parasitize $A$. parasiticum irrespective of the associated arthropod. A. parasiticum has been isolated in axenic culture previously (Whisler 1960, 1962, 1978, Lichtwardt 1986). Although attempts to isolate Amoebidium were unsuccessful, future isolation attempts are warranted because dual culture of Basidiolum with its Amoebidium host would make additional studies of this rare and obscure parasite possible.

My observations of $B$. fimbriatum, including attachment, penetration, thallus development and haustorial ramification resulting in death of $A$. parasiticum, support Cienkowski's observations. These photomicrographic images of $B$. fimbriatum are the only depictions of this fungus other than Cienkowski's original drawings. It is worthwhile to reiterate and discuss some of the key points and observations made in the original report. Owing to the obscurity of the parasitic fungus, some of Cienkowski's (1861) drawings of B. fimbriatum have been copied and rearranged as Figs 14-20. In the following synopsis, Cienkowski's descriptive assessment and terminology are consolidated with a modern interpretation (parenthetically) that has been used above.

Cienkowski (1861) recognized the parasite of $A$. parasiticum by the altered condition of the commensals on mosquito exuviae. The accuracy of the original observations and illustrations, obviously from detailed and careful examination of the specimens, deserve further comment. Some specimens of $A$. parasiticum bore pearshaped structures, with fine granularity, attached laterally or terminally (Figs 14-17). These structures had wart-like protuberances (Fig. 14a-c) on their distal surface lending some similarity to the basidium of 


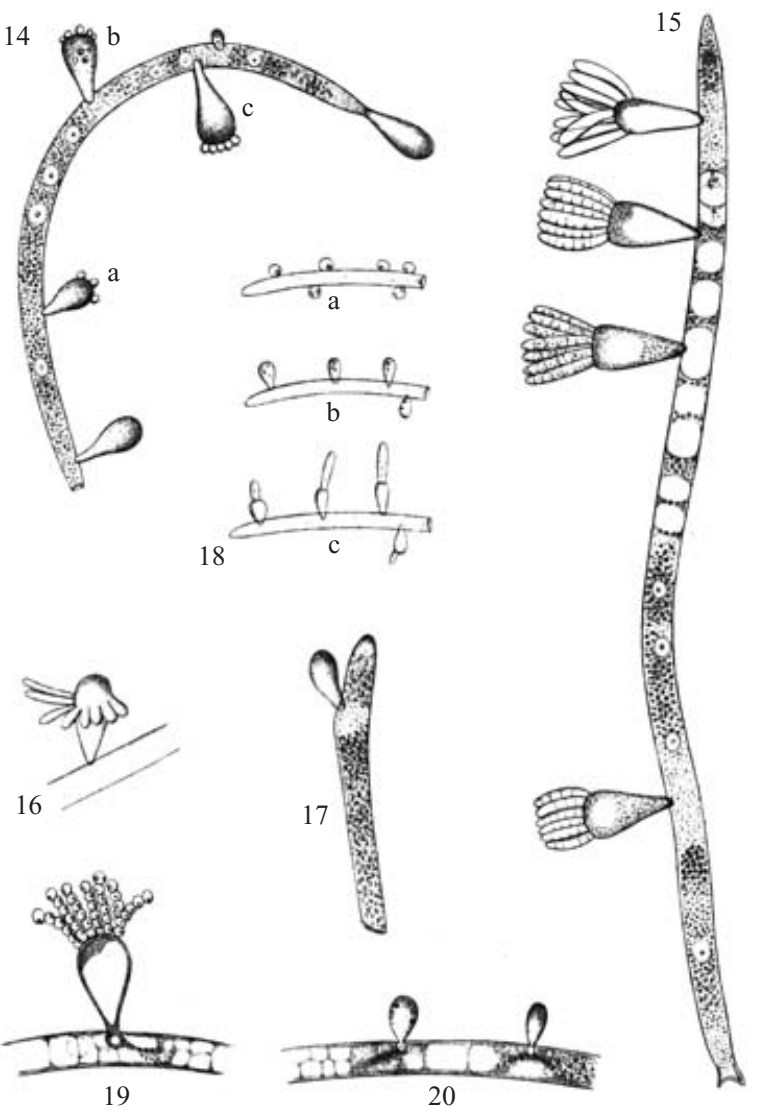

Figs 14-20. Structure and development of Basidiolum fimbriatum on thalli of Amoebidium parasiticum, copied and rearranged from Cienkowski's (1861) plate. Fig. 14. Pear-shaped thalli, some with protuberances just prior to sporulation $(\mathrm{a}-\mathrm{c})$, attached laterally and terminally. Fig. 15. Four laterally attached thalli with rod shaped structures (merosporangia) that have developed from protuberances. Fig. 16. Immature thallus with successive sporangial formation just below the vertex. Fig. 17. Single immature thallus causing host wall distortion at attachment site. Fig. 18a-c. Sequential series showing restricted growth form on immature host thalli. Figs 19-20. Attached thalli with ramifying haustoria emanating from small swelling inside the host. (No scale bars indicated on original; drawn at $\times 285$.)

higher fungi. Straight to curved rod shaped merosporangia, arising from the wart-like protuberances (Fig. 15), were ultimately partitioned by lateral fission with a beaded appearance (Fig. 19). Swollen spores ultimately became a loose mass with no apparent motility, yet attached to thalli to continue the parasitic life cycle (Figs 14, 20). Cienkowski (1861) also noted that the spores had small 'dots' embedded in their interior.

Cienkowski (1861) observed, over several days, that thalli could undergo repeated sporulation. The first row of rods (merosporangia) attached slightly below the vertex (Fig. 16). Secondary merosporangia, thicker then their predecessors, formed toward the centre of the distal surface. All stages of development of B. fimbriatum were observed to be at random on $A$. parasiticum thalli of various sizes and maturity, including young thalli (Fig. 18) but were more commonly found on larger ones
(Figs 14-15, 17). Immature thalli, even with only one or two sporangia, underwent sporulation, ultimately with spores separating as spherical bodies (Fig. 18a-c).

Initially, Cienkowski was not certain whether the filamentous root was of parasitic origin or if it represented the condensed content of the Amoebidium (Figs 19-20). Uninterrupted examination of several attached spores provided conclusive evidence of the former. Several attached spores transformed after about twenty hours into the pyriform sporophore (Fig. 20). Within a few hours, rod-shaped sporangia developed and matured before disintegrating into pea-like spherical bodies (Fig. 19). Cienkowski was convinced of the parasitic nature of $B$. fimbriatum on $A$. parasiticum because it possessed a penetrating, root-like growth (i.e. haustorial) that was accompanied by loss of (healthy) host granularity, it often distorted the host thallus and no amoeboid cells were ever observed from infected thalli.

Cienkowski concluded that Basidiolum possessed a spore development that argued for its placement in the fungi, but that too little was known of its development to place it within the groups that were known at the time. The name B. fimbriatum was proposed on the basis of thallus shape and sporulation ontogeny, but the question of the natural affinity of this unusual parasite has remained unanswered to date. Therefore, I conclude with a morphologically based attempt to place $B$. fimbriatum in the realm of contemporary fungal systematics.

The spore forming structures of $B$. fimbriatum, merosporangia, are elongate endospore-forming structures, more or less cylindrical in multispored forms, with either an evanescent or persistent wall (Benny et al. 2001). According to Benny et al. (2001), merosporangia are formed in one family (Syncephalastraceae) of the Mucorales and in the Dimargaritales, Kickxellales and possibly the Zoopagales.

The Syncephalastraceae possess merosporangia but belong to a broader group (Mucorales) of facultative, non-haustorial parasites. The Dimargaritales are all haustorial parasites, but on other fungi, especially the Mucorales, and not protists. Further, they possess twospored merosporangia or simple, branched sporiferous branchlets that arise from inflated or unmodified sporophore apices. The Kickxellales are characterized by unispored sporangia that are usually released in a droplet of fluid but may be dry and possess spines and warts. Most Kickxellales are isolated from dung but may be obtained from soil as well. Therefore, I suggest that of all the merosporangiferous fungi, the Zoopagales sensu Benjamin (1979) includes members that are most similar to B. fimbriatum.

The Zoopagales sensu Benjamin (1979) are soil borne, obligate parasites of other fungi or small animals, including amoebae, with ectoparasites forming haustoria in the host. The thallus is a branched or unbranched inflated hyphal coil in the hosts and asexual reproduction is by multispored merosporangia or conidia (Benny et al. 2001). While these features have 
been noted for $B$. fimbriatum, the precise placement among the five families (Cochlonemataceae, Helicocephalidaceae, Piptocephalidaceae, Sigmoideomycetaceae and Zoopagaceae) of Zoopagales, as presented in Benny et al. (2001), is difficult.

The Cochlonemataceae are parasites of amoebae, as well as nematodes and rotifers. Fertile hyphae or spores are found outside the host while the vegetative thallus may be completely internal. The Zoopagaceae include predaceous forms of these parasites. In Helicocephalidaceae, all species appear to be haustorial parasites of nematodes and their eggs. The Sigmoidiomycetaceae and Piptocephalidaceae are mycoparasites; the latter are all biotrophic, haustorial mycoparasites, mainly on Mucorales. Members of the Piptocephalidaceae have relatively fine somatic hyphae, a simple sporangiophore with the merosporangia (nearly all are multispored) borne on a terminal vesicle. Syncephalis and Piptocephalis, the most commonly recognized genera of the order, are relatively large and include a number of species. Both genera are culturable, although Syncephalis is more difficult, growing best on the original host. Additionally, Syncephalis includes smaller species, making them difficult to find and maintain (Benny et al. 2001).

Lichtwardt $(1960,1986)$ has noted the resemblance of $B$. fimbriatum to the merosporangia-bearing, terminal vesicle of a hypothetical sessile Syncephalis. Although I concur with this view, I decline at this time to place Basidiolum in the Piptocephalidaceae, despite that it may be the most appropriate of the five families. Basidiolum differs from all of the Piptocephalidaceae in that it is a protist parasite. While some members of the Zoopagales are known to parasitize amoebae, they differ morphologically. Finally, the absence of sexual production among the specimens of Basidiolum precludes any further speculation of possible fungal relationships. Therefore, based on habit and morphological criteria, I suggest that $B$. fimbriatum conforms with the description of the order Zoopagales sensu Benjamin (1979).

The exact placement of this parasitic fungus should be possible using molecular systematic techniques, especially as databases are expanding to include members of the Zoopagales, amongst the Zygomycota (Tanabe et al. 2000). Unfortunately, at the time of collection, too few specimens were available to preserve material for molecular analysis. If specimens of $B$. fimbriatum become available with future collections, DNA sequence data will test its hypothesized placement among the Zoopagales sensu Benjamin (1979). It is hoped that this report will help to stimulate the pursuit of this and other obscure fungi by those who are willing to seek them in the spirit of those who have already seen them.

\section{ACKNOWLEDGEMENTS}

This investigation is part of an ongoing research program (http:// www.nhm.ukans.edu/ fungi) supported by a National Science Foundation PEET Award (DEB-9521811) issued to Robert W. Lichtwardt and Leonard C. Ferrington jr. I appreciated the enthusiasm and assistance of my class in collecting the specimens. I am indebted to Michael Krings and Susanne Hauswaldt for their patience and efforts in translating Cienkowski's original German. Richard K. Benjamin has graciously given advice on earlier interpretations and supplied negatives of several species of Syncephalis for comparative purposes. Lichtwardt and Lois Tiffany kindly permitted the inclusion of their data on the occurrence in Iowa. The comments and suggestions of Robert Lichtwardt, Richard Benjamin and Gerald Benny improved the manuscript. I must also thank Matías Cafaro and Paula Clarke who proofread earlier versions of the paper. Finally, Robert Lichtwardt is graciously acknowledged for first directing me to the literature on this obscure parasite, indicating its rarity but prior occurrence and for his enthusiastic support toward all aspects of this contribution.

\section{REFERENCES}

Benjamin, R. K. (1979) Zygomycetes and their spores. In The Whole Fungus (B. Kendrick, ed.): 573-616. National Museum of Natural Sciences, Ottawa.

Benny, G. L., Humber, R. A. \& Morton, J. B. (2001) ['2000’] Zygomycota: Zygomycetes. In The Mycota. Vol. 7A, Systematics and Evolution (D. J. McLaughlin, E. G. McLaughlin \& P. A. Lemke, eds): 113-146. Springer-Verlag, Berlin.

Benny, G. L. \& O'Donnell, K. (2000) Amoebidium parasiticum is a protozoan, not a trichomycete. Mycologia 92: 1133-1137.

Cienkowski, L. (1861) Ueber parasitische Schläuche auf Crustaceen und einigen Insektenlarven (Amoebidium parasiticum m.). Botanische Zeitung 19: 169-174.

Hawksworth, D. L., Kirk, P. M., Sutton, B. C. \& Pegler, D. N. (1995) Ainsworth \& Bisby's Dictionary of the Fungi. 8th edn. CAB International, Wallingford.

Lichtwardt, R. W. (1960) Taxonomic position of the Eccrinales and related fungi. Mycologia 52: 410-428.

Lichtwardt, R. W. (1986) The Trichomycetes: fungal Associates of Arthropods. Springer-Verlag, New York.

Lieberkühn, N. (1856) Ueber parasitische Schläuche auf einigen Insectenlarven. Archiv für Anatomie, Physiologie und Wissenschaftliche Medicin 25: 494-495.

Mendoza, L., Taylor, J. W. \& Ajello, L. (2002) The class Mesomycetozoa: a heterogenous group of microorganisms at the animalfungal boundary. Annual Review of Microbiology 56: 315-344.

Misra, J. K. \& Lichtwardt, R. W. (2000) Illustrated Genera of Trichomycetes. Science Publishers, Enfield, NH.

Schenk, A. (1858) Ueber parasitische Schläuche auf Crustaceen. Physikalisch-Medizinische Gesellschaft 8: 252-259.

Tanabe, Y., O'Donnell, K., Saikawa, M. \& Sugiyama, J. (2000) Molecular phylogeny of parasitic Zygomycota (Dimargaritales, Zoopagales) based on nuclear small subunit ribosomal DNA sequences. Molecular Phylogenetics and Evolution 16: 253-262.

Ustinova, I., Krienitz, L. \& Huss, V. A. (2000) Hyaloraphidium curvatum is not a green alga, but a lower fungus; Amoebidium parasiticum is not a fungus, but a member of the DRIPs. Protist 151: 253-262.

Whisler, H. C. (1960) Pure culture of the Trichomycete, Amoebidium parasiticum. Nature 186: 732-733.

Whisler, H. C. (1962) Culture and nutrition of Amoebidium parasiticum. American Journal of Botany 49: 193-199.

Whisler, H. C. (1978) Amoebidium parasiticum. In Lower Fungi in the Laboratory (M. S. Fuller, ed.): 165-166. University of Georgia, Athens, GA.

Whisler, H. C. \& Fuller, M. S. (1968) Preliminary observations on the holdfast of Amoebidium parasiticum. Mycologia 60: 1068-1079.

White, M. M. (1999) Legerioides, a new genus of Harpellales in isopods and other Trichomycetes from New England, USA. Mycologia 91: 1021-1030.

Williams, M. C. \& Lichtwardt, R. W. (1993) A new monotypic fungal genus, Allantomyces, and a new species of Legeriomyces (Trichomycetes, Harpellales) in the hindgut of a Western Australian mayfly nymph (Tasmanocoenis sp.). Canadian Journal of Botany $\mathbf{7 1}$ : 1109-1113.

Corresponding Editor: D. L. Hawksworth 